\section{0년대의 결핵치료}

(사나토륨 치료가 없어진 다음)

\section{Care of Tuberculosis Patients in the 1970's after the Sanatorium, then What? (Editorial)}

\author{
Stead, W. W.
}

Chest, 1971-10, 60:309

결핵치료는 아직도 간단하게 단기간에 끝낼 방법이 없다. 치료에 성공하는 비결은 여러가지의 화학약품들 을 치료초기에는 강력하게 사용하고 그 훙에는 대체로 정상생활은 할 수가 있어도 약은 아직도 퍽 오래동안 계속하도록 하는데 있다.

결핵화학요법이 발달 보급되면서부터 사나토륨(결핵 병원)에서의 입원치료의 필요성이 많이 감소되고 또 장 기간의 안정요법이 불필요하게된 것은 사실이다. 이러 한 소위 결핵을 결핵 전문병원에서만 치료하던 요양소 위주 시대가 지나고 난 다음 현시기에 있어서의 결핵치 료는 일반 종합병원에서 맡아서 하기로 되어 있다. 그 러나 여기에는 몇가지 중요한 문제들이 남아 있으며 최 소한도의 기준을 지키지 않는다면 결핵치료는 제대로 시행되지 못할 위험성이 다분히 있다.

결핵진단과 치료의 최소 필수 조건

(1) 계속적이고 원활하게 그리고 조직적으로 결핵환자 의 치료와 세균학적 검사가 시행되어야 한다.

자각증싱이 없다던지 혹은 반성적인 결핵환자에 대해 서는 특별한 고려와 조치가 필요한데 일반 병원에서는 혼히 다른 바뺀일들에 쫓겨서 혹은 더욱 흥미있는 병들 을 연구하기 위해서 이러한 결핵환자들에 대해서는 무 성의하게 되기가 매우 섭다. 따라시 검사는 제대로 안 되고 치료는 중단되기가 싑나.

(2) 초기 진단과 화학요법의 시작 혹은 감염위험성의 유무를 결정하기 위해서 필요한 단기간 동안의 입원을 할 수 있도록 하는 시설의 확보가 필요하다.

(3) 전속이 아니라도 좋으나 결핵환자를 다루는데 경 험이 있는 의사와 간호원 그리고 사회사업계원이 포함
된 결핵팀이 있어야 한다.

(4.) 결핵환자가 자진해서 치료를 잘 계속할 수 있도록 하기 위한 계몽과 지도 교육을 할 수 있어야 한다. 결 핵의 치료나 예방을 그들 자신에게만 맡겨 놓을 수 없 는 것은 잘 아는 일이다.

(5) 결핵세균검사의 시설과 인원 확보

(6) 주거지 보건소와 연락을 긴밀히 해서 환자의 발견 과 그 동태 그리고 가족이나 접촉자들에 대한 검진을 철저이 하고 또 통원치료 환자에 있어서는 그 치료계속 을 독려할 수 있도록 하기 위해서도 가정빙문제도를 잘 해야 한다.

(7) 알콜중독자나 기다 정신상태가 온전하지 못한 환 자들에 대한 특별지도,

이상과 같은 필수조건이 구비되지 않고는 결핵치료는 제대로 될 수가 없다. 현재의 결핵치료 제약에 대한 효 력을 과신하고 또한 결핵병태를 잘 이해하지 못하는 사 람들은 결핵치료를 마치 폐염이나 충수염의 치료와 같 이 간단하게 생각하는 과오를 범하고 있다. 일반급성치 료 하는데 있어서는 계속적인 관찰과 지도가 별로 필요 하지 않지만 결핵은 그렇지가 않다.

그 이유는 결국 결핵의 진단이 그리 쉅게 조기에 이 뤄질 수가 아직은 없고, 따라서 아직도 다른 병들에 비 해서는 만성적인 경과를 취하게 되고 또 현재 우리들이 사용하는 결핵치료약들은 물론 매우 효과적인 것이기는 하지만 그러나 아직도 하루 이틀 혹은 일이주일 안에 병을 근치할 수 있을 정도는 못되기 때문이라고 하겠다 그런데 이러한 비슷한 문제는 결핵 이외에도 예를 들면 산부인과에서의 임산부의 계속 관찰이라던지 만성신장 염이나 심장병에 대한 특별한 지도 관찰이라던지 여러 가지의 경우도 있으면 이러한 때는 역시 전문의의 주의 깊은 지도와 환자들의 꾸준한 노력이 절대로 필요한 것 이다.

따라서 결핵은 아무나 아무데서나 치료하면 된다는 싱각은 시정되어야 할 것이고 역시 몇몇 지정된 종합병 원에서 충분한 시설과 체계를 세워서 결핵환자를 다궈 야 될 것이다.

〈역자주역〉 이상에서는 상당히 많은 부분에서 이해 를 쉽게 하기 위해서 초역자가 말을 많이 보탰지만 또 우리나라의 현상을 좀 언급해 보고자 한다. 
$\mathrm{WHO}$ 의 결핵정책지도의 주요 골자는 통원치료이 고 결핵사업을 일반 의료사업 속에다 병합해야 한다 (Integration)는 것이라고 하겠는데 그렇다면 우선 정 확한 진단과 초치료시에 있어서의 감시와 계몽지도가 얼마나 어려운가를 알아야 하겠다. 선진국가에서는 돈 이 있어서 뿐 아니라 진단의 정확성과 치료 예방의 철 저를 위해서 단기간의 입원을 필요하다고 하는데 우리 나라에서는 무조건 통원치료만이라고 한다면 과연 모든 점에서 뒤떨어진 환자들과 검사시설을 가지고 통원외래 제도에서 이러한 일이 잘 이행될지 문제라고 안 할수가 없을 것이다. 저자의 경험으로 바도 소위 대학병원 외 래에서 결핵환자의 객담검사 실시비율은 $30 \sim 40 \%$ 를 넘 지 못했는데 이것은 결국 의사의 무성의와 환자의 비협 력 혹은 몰이해에서 오는 결함이라고 할 수 밖에 없다. 계속 치료에 관한 문제도 마찬가지로서 의사의 성의 있 는 설득에 의해서 환자의 노력을 꾸준하게 지속시키지 못한다면 이것은 불가능한 것이다.

환자를 계몽하고 지도하는데는 역시 전문적인 경험이 있는 의사의 성의가 필요한 것이고 이러한 목적을 달성 하기에는 역시 과거와 같은 결핵전문병원의 환경이 매 우 편리한 것이 틀림없는 사실이고 그렇지 못하면 적어 도 특별한 경험과 성의를 가지고 있는 의사의 지도가 절대로 필요한 것이다. 우리나라와 같이 결핵환자가 많 은 고장에서는 모든 의사가 다같이 결핵환자를 잘 지도 할 수 있는 능력을 갖추고 있으먼 이상적이겠지만 그러 나 각의사가 다 그렇게 되기는 어려운 것이고 따라서 결국은 결핵을 전공하는 의사가 따로 있게 되는 것이 당연한 일일 것이다. 그렇다고해서 결핵지식을 전공의 사들만이 고수한다는 의미는 절대로 아니다. 결핵이외 에도 모든 문제는 각기 전공분야로 될 수 있을 것이고 특히 그 문제가 중대하면 할수록 또 그러한 문제가 많 으면 많을 수록 전공자가 많아질 것이다. 따라서 결핵 문제가 적어진 선진국에서는 결핵전공병원이 불필요하 겠지만 우리나라와 같이 결핵이 많은데서는 아직도 결 핵병원과 결핵전문의가 많이 필요하고 정부의 보건정책 을 수립하는데 있어서도 결핵에다 중점을 두지 않을 수 가 없을 것이다.

따라서 우리나라의 보건예산 중에서 차지 하는 결핵 예산이 큰 것은 당연한 일이다. 그러나 한쪽으로는 또 선진국의 풍조가 그대로 수입되어서 일반 의료기관이나 의학교육에 있어서 결핵을 소홀하게 다루고 있는 것도 사실이다. 더구나 종합병원에서나 대학병원에서는 결핵 환자의 입원을 꺼려하고 있고 한쪽에서는 또 결핵은 통 원치료 만으로 될 수 있다고 주장을 하고 있으므로 젊
은 의사들이 결핵을 제대로 이해하기는 매우 어렵게 되 었다고 할 수 있다. 수천만불이 요구되는 지하철공사는 당연한 것 같이 받아 드리면서 수백만불이면 충분히 완 전한 방법으로 될 수 있는 결핵사업에 대해서는 정부예 산이 없다. 혹은 나라자체가 가난하다는 등의 구실을하 면서 인색하기가 짝이 없는 태도를 WHO 의 결핵전문 가라는 사람들이 아무 비평없이 받아드릴 뿐 아니라 오 히려 그렇게 적은 예산을 가지고도 결핵사업은 충분히 될 수 있는 것 같은 인상을 풍기고 있다는 점은 참으로 이해하기가 곤난하다. Stead 가 여기 말하는 것 이외에 도 또 우리들이 생각해야할 중대한 문제는 현재 유행되 고 있는 소위 수익자 부담 제도라는 악질이 결핵사업에 있어서도 전염되어 있다는 점이다. 결핵환자 중에서 자 기의 치료비를 전담할 수 있는 사람은 극히 소수 뿐이 다. 정부가 돈이 없다면 국민은 돈 돌리기가 더 어려운 것이고 일부 돈 많은 사람만이 결핵을 알았으면 수익자 부담을 하는데 좋겠지만 사실은 정반대이다. 그러므로 미국과 같이 자유 자본주의를 선전하는 나라에서도 결 핵 사업단은 거의 전부를 공공부담으로 하고 이밖에도 또 환자 가족의 생계보조까지도 해주므로써 장기간의 치료와 병균의 전파를 방지하도록 노력하고 있는 것이 다 그런데도 불구하고 인간을 대상으로 하는 결핵의 치료와 예방은 그리 쉬운 것은 아니다. 그렇다면 과연 통원치료 만을 하고 결핵치료약의 공급도 부족하고 환 자의 발견도 객담검사를 위주로해서 이미 중병환자가 된 후에만 치료대상으로 선정하는 것으로써 만족하는 것은 백년후에나 개울물이 맑아지기를 기다린다는 격언 과 같다고 비판을 안받을 도리가 없을 것이다.

$$
\text { <초역자:이 찬 }
$$

세〉

$$
\text { 보건의료의 실천 }
$$

<수공업식에서 대공업식으로>

\begin{tabular}{|} 
Delivery of Health Services, from \\
Handicraft to Industry in Medicine. \\
Holm, J. \\
International Tuberculosis Digest 6 \\
IUAT, 1971-6
\end{tabular}

오늘날 결핵관리에 있어서 중요한 문제는 의학적 기 술적인 것이 아니고 이미 잘 알고있는 결정적 방법들을 어떻게 잘 실천에 옮길 수 있느냐 하는것(Operational) 이라고 하겠다. 